\title{
POTENTIOMETRIC GAS SENSING ELECTRODES
}

\author{
J. W. Ross, J. H. Riseman and J. A. Krueger \\ Orion Research Inc., Cambridge, Mass., U.S.A.
}

\begin{abstract}
A number of potentiometric gas sensing electrodes using a hydrogen or other ion sensing electrode and a gas permeable membrane have been studied. A theoretical model has been developed describing the time response, electrical potential behaviour and limit of detection as a function of membrane properties, geometry, and internal electrolyte composition. Electrodes responding to carbon dioxide, ammonia, amines, sulphur dioxide, nitrogen dioxide, hydrogen sulphide, hydrogen cyanide, hydrogen fluoride, acetic acid, and chlorine have been constructed and their response characteristics are found to be in good agreement with the theoretical predictions.
\end{abstract}

\section{INTRODUCTION}

Clark $^{1}$ was the first to use an electrochemical sensor coupled with a gas permeable membrane. He placed a platinum electrode behind a membrane with a thin layer of an indifferent electrolyte interposed between the platinum surface and the membrane. Oxygen diffusing through the membrane was detected polarographically. The electrode has found wide application but suffers from an inherent difficulty in that oxygen is being continuously consumed during the measurement. The measured current therefore is sensitive to rates of stirring in the sample solution and changes in membrane thickness, as well as the level of oxygen.

The disadvantages of the polarographic approach are not present in the later carbon dioxide electrode model ${ }^{2}$. The polarographic electrode was replaced by a glass $\mathrm{pH}$ sensing electrode and a dilute sodium bicarbonate solution was used as the internal electrolyte. (Figure 1). Carbon dioxide diffuses through the membrane until equilibrium is established in the thin internal electrolyte layer. At equilibrium (provided the carbon dioxide concentration is not too low) the $\mathrm{pH}$ of the internal electrolyte is given by the simple mass action expression as shown in Figure 1. The response of the electrode to carbon dioxide is essentially Nernstian and is a direct measure of the carbon dioxide level in the sample. The important advantage of this approach is that except for a brief period while equilibrium is being established, there is no consumption of carbon dioxide from the sample and electrode calibration is independent of rates of stirring and membrane thickness.

In spite of the wide use of the Severinghaus electrode, very little work has been done to extend the approach to the measurement of other species and only recently has an ammonia sensing electrode been reported ${ }^{3}$ which uses the basic Severinghaus idea but a different internal electrolyte and membrane 


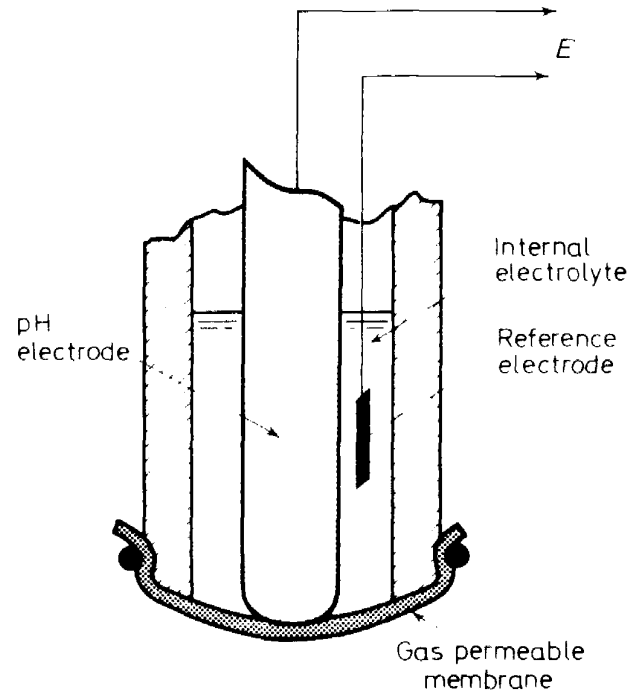

Figure 1. Severinghaus carbon dioxide electrode and equations describing electrode response.

$$
\left[\mathrm{H}^{+}\right]=\frac{K_{1}\left[\mathrm{H}_{2} \mathrm{CO}_{3}\right]}{\left[\mathrm{HCO}_{3}\right]}=\frac{K_{1} K_{4}\left[\mathrm{CO}_{2}\right]}{\left[\mathrm{HCO}_{3}\right]}: E=\text { const. }+\frac{R T}{F} \ln \left[\mathrm{CO}^{2}\right]
$$

material. In view of the recent advances in both electrode and membrane technology it is obvious that many further extensions to other species are possible, a few of which are here described. The design problem in developing an electrode for a given species is first to find a permeable membrane for the species and second, to find an internal electrolyte in which the diffusing species participates in an equilibrium involving an ion which can be directly measured by an ion selective electrode. The recent availability of microporous hydrophobic membranes has provided a membrane system into which any species having a measurable vapour pressure over a sample solution will diffuse. The large number of new ion selective electrodes has greatly simplificd

Table 1. Possible equilibria associated with gas sensing electrodes

\begin{tabular}{|c|c|c|}
\hline diffusing species & equilibria & sensing electrode \\
\hline $\mathrm{NH}_{3}$ & $\begin{array}{l}\mathrm{NH}_{3}+\mathrm{H}_{2} \mathrm{O} \cdot \mathrm{NH}_{4}^{+}+\mathrm{OH} \\
x \mathrm{NH}_{3}+\mathrm{M}^{n+} \cdot \mathrm{M}\left(\mathrm{NH}_{3}\right)_{\mathrm{x}}^{n^{+}}\end{array}$ & $\begin{array}{l}\mathrm{H}^{+} \\
\mathrm{M}=\mathrm{Ag} \\
+\mathrm{Cd}^{2+} \cdot \mathrm{Cu}^{2+}\end{array}$ \\
\hline $\mathrm{SO}_{2}$ & $\mathrm{SO}_{2}+\mathrm{H}_{2} \mathrm{O} \cdot \mathrm{H}^{\prime}+\mathrm{HSO}_{3}$ & \\
\hline $\mathrm{NO}_{2}$ & $2 \mathrm{NO}_{2}+\mathrm{H}_{2} \mathrm{O} \cdot \mathrm{NO}_{3}+\mathrm{NO}_{2}+2 \mathrm{H}^{+}$ & $\mathrm{H}^{+} . \mathrm{NO}_{3}$ \\
\hline $\mathrm{H}_{2} \mathrm{~S}$ & $\mathrm{H}_{2} \mathrm{~S}+\mathrm{H}_{2} \mathrm{O} \cdot \mathrm{HS}+\mathrm{H}^{+}$ & $S^{2}$ \\
\hline $\mathrm{HCN}$ & $\mathrm{Ag}\left(\mathrm{CN}_{2}\right)^{-} \cdot \mathrm{Ag}{ }^{1}+2 \mathrm{CN}$ & $A g^{+}$ \\
\hline $\mathrm{HF}$ & $\begin{array}{l}\mathrm{HF} \mathrm{H}+\mathrm{F}^{3} \\
\mathrm{FeF}_{x}^{2} \mathrm{FeF}_{y}^{y}+(x-y) \mathrm{F}\end{array}$ & $\begin{array}{l}F \\
P t(\operatorname{redox})\end{array}$ \\
\hline HOAc & HOAC $\cdot H^{+}+O A C$ & $\mathrm{H}$ \\
\hline $\mathrm{Cl}_{2}$ & $\mathrm{Cl}_{2}+\mathrm{H}_{2} \mathrm{O}: 2 \mathrm{H}^{+}+\mathrm{ClO}+\mathrm{Cl}$ & $\mathrm{H}^{*}, \mathrm{Cl}$ \\
\hline $\mathrm{CO}_{2}$ & $\begin{array}{l}\mathrm{CO}_{2}+\mathrm{H}_{2} \mathrm{O} \mathrm{H}^{+}+\mathrm{HCO}_{3} \\
\mathrm{X}+\mathrm{H}+\mathrm{O} 2 \mathrm{H}^{+}+\mathrm{XO}+\mathrm{X}\end{array}$ & $\mathrm{H}^{+}-\mathrm{Br}$ \\
\hline
\end{tabular}


the problem of devising suitable electrolyte solutions. Table 1 gives a number of potentially useful systems which could serve as analytical devices. The list is by no means complete, and is only intended to be illustrative.

\section{STEADY STATE MODEL}

The behaviour of a gas sensing electrode, particularly its time response, sensitivity and limits of detection, depends in a complex way on the variables of geometry, membrane properties and the internal electrolyte used. In order to determine the relative effect and importance of these variables, we shall first consider an electrode which is in equilibrium with a sample solution having a concentration $C_{1}$ of a species to which the electrode membrane is

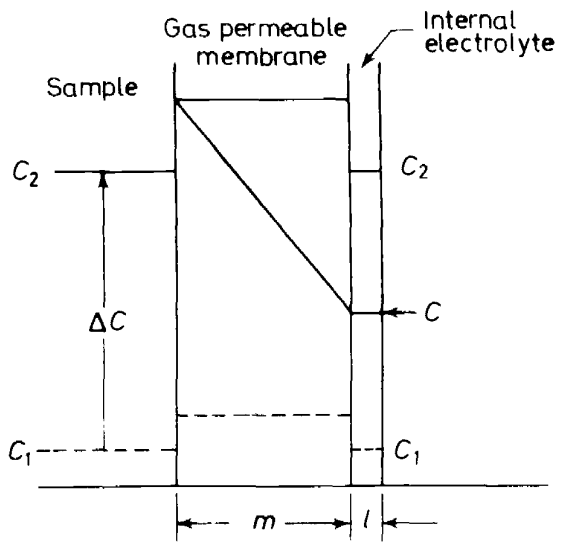

Figure 2. Steady state model for electrode response.

permeable. The concentration of the diffusing species will also be $C_{1}$ in the internal electrolyte. (See Figure 2). The concentration of the species in the membrane will be $\bar{C}$ where

$$
\bar{C}=k C
$$

and $k$ is the partition coefficient of the species between the aqueous sample, internal electrolyte phase and the membrane phase.

At time $t=0$ we suddenly change the concentration in the sample solution to $C_{2}$. We now assume that the partition equilibrium at the membrane interface is very rapid, in which case the concentration $\bar{C}$ in the membrane at the interface will immediately change to a new value $\bar{C}_{2}$. In general this assumption is valid. However, there is one important exception; the solutiongas equilibrium with carbon dioxide is slow, and, as such, may limit the electrode time response.

A concentration gradient now exists in the membrane and a net flux of the diffusing species will exist. As a result, the concentration, $C$, of the species in the internal electrolyte will change from its initial value in the direction of 
the new equilibrium value $C_{2}$. If we now assume that the membrane thickness, $m$, is small, that the thickness, $l$, of the internal electrolyte is much smaller than $m$, and further, that the diffusion coefficient $D$ in the membrane phase is not too small, then a steady state situation will be rapidly set up in the membrane in which the diffusion species will flow down a linear concentration gradient. Applying Fick's law, we have for an electrode of area $A$

$$
\text { Flux }=-\frac{A D \Delta \bar{C}}{m}
$$

where $\Delta \bar{C}$ is the difference between $\bar{C}$ at the inside interface and $\bar{C}_{2}$ at the outside interface.

In the internal electrolyte the species diffusing through the membrane can exist in a number of forms, either as the neutral species or as various ionized or complexed species. Let

$$
C_{\mathrm{T}}=C+C_{\mathrm{B}}
$$

where $C$ is the concentration of the neutral species and $C_{\mathrm{B}}$ is the sum of the concentrations of all the other forms. $C_{\mathrm{T}}$ then is the total concentration of the diffusing species in the internal electrolyte. As a result of the flux, a change in the total number of moles $\left(A l C_{\mathrm{T}}\right)$ of the species will occur in the internal electrolyte given by

$$
A m \frac{\mathrm{d} C_{\mathrm{T}}}{\mathrm{d} C}=\text { Flux }
$$

Combining equations $1,2,3$ and 4

$$
\frac{\left[1+\left(\mathrm{d} C_{\mathrm{B}} / \mathrm{d} C\right)\right] \mathrm{d} C}{C_{2}-C}=-\frac{D k}{\operatorname{lm}} \mathrm{d} t
$$

We now define $\varepsilon$ as the fractional approach to equilibrium, i.e.,

$$
\varepsilon=\left|\frac{C_{2}-C}{C_{2}}\right|
$$

Substitution in equation 5 yields

$$
\left[1+\frac{\mathrm{d} C_{\mathrm{B}}}{\mathrm{d} C}\right] \mathrm{d} \ln \varepsilon=-\frac{D k}{\operatorname{lm}} \mathrm{d} t
$$

In general, integration of equation 7 requires a knowledge of $\mathrm{d} C_{\mathrm{B}} / \mathrm{d} t$ which in principal can be obtained from the internal electrolyte composition and all the equilibrium constants describing the species contributing to $C_{\mathrm{B}}$. In practice this is extremely difficult to do so we will consider the simple case in which either

(a) $\frac{\mathrm{d} C_{\mathrm{B}}}{\mathrm{d} C} \ll 1$ or

(b) the range $C_{2}-C_{1}$ is sufficiently small so that $\mathrm{d} C_{\mathrm{B}} / \mathrm{d} C$ can be considered a constant. 


\section{GAS ELECTRODFS}

Under these restrictions the integration of equation 7 is readily performed and

$$
t=\frac{\operatorname{lm}}{D k}\left[1+\frac{\mathrm{d} C_{\mathrm{B}}}{\mathrm{d} C}\right] \ln \frac{\Delta C}{\varepsilon C_{2}}
$$

For analytical purposes it is generally most convenient to speak of $t_{0.01}$ as the time required to reach $99 \%$ of equilibrium, where $\varepsilon=0.01$.

Equation 8 predicts at least one interesting feature which is not immediately obvious. The time response will depend on the direction of the concentration change. In going from a very low to a high concentration where $C_{2} \gg C_{1}, \Delta C$ will be equal approximately to $C_{2}$. Under these conditions the time response will be nearly independent of the magnitude of the concentration change. For the reverse process, however, $\Delta C$ will be approximately equal to $C_{1}$ and the time response will vary with the ratio, $C_{1} / C_{2}$. The effect should be considerable, as shown in Figure 3 where $t_{0.01}$ is approximately thirteen times greater in going from a concentration of $10^{-1} \mathrm{M}$ to $10^{-5} \mathrm{M}$ than for the reverse process.

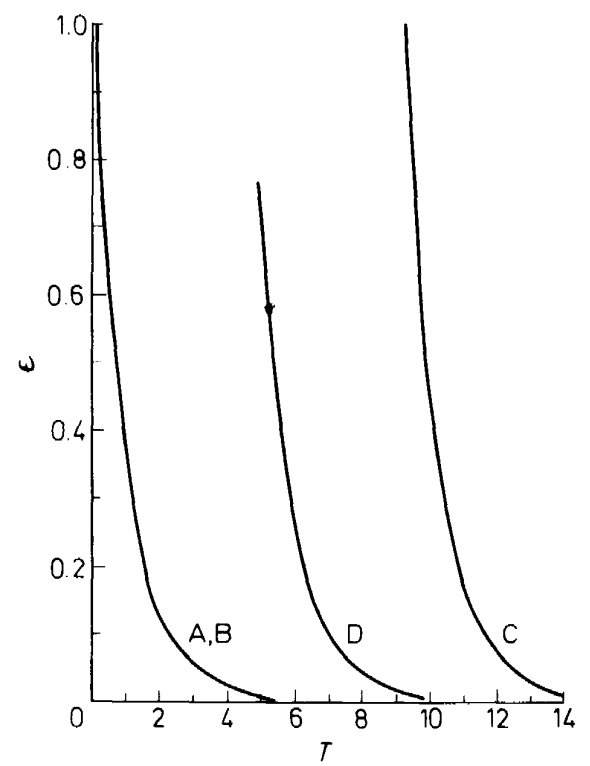

Figure 3. Fractional deviation from equilibrium versus $T$, for various values of $C_{1}$ and $C_{2}$.

$\begin{array}{ll}\mathrm{A} & C_{1}=10^{-5} \mathrm{M} \\ \mathrm{B} & C_{1}=10^{-3} \mathrm{M} \\ \mathrm{C} & C_{1}=10^{-1} \mathrm{M} \\ \mathrm{D} & C_{1}=10^{-1} \mathrm{M}\end{array}$

$C_{2}=10^{-1} \mathrm{M}$
$C_{2}=10^{-1} \mathrm{M}$
$C_{2}=10^{-5} \mathrm{M}$
$C_{2}=10^{-3} \mathrm{M}$

$T_{0.01}=4.6$

$T_{0,01}=4.6$

$T_{001}=13.8$

$T_{0,01}=9.2$

$\frac{\mathrm{d} C_{\mathrm{B}}}{\mathrm{d} C}=0$

$T=\frac{D k}{l m} t$ 
To summarise, the model as described by equation 8 predicts the effects of geometry, $(\mathrm{lm})$ : membrane characteristics. $(D k)$ : electrolyte composition. $\mathrm{d} C_{\mathrm{B}} / \mathrm{d} C$ : and experimental conditions, $\Delta C / C_{2}$, on the time response of the electrode.

\section{MEMBRANE CHARACTERISTICS}

Two categories of membranes are available for gas electrode construction. The first comprises heterogeneous microporous membranes which are not wetted by contact with an aqueous phase. In these membranes, which are available in a wide variety of materials (cellulose acetate, Teflon, polyvinyl chloride, polyvinyl fluoride. polypropylene, and polyethylene), the diffusing species crosses the membrane in the gas phase. We will refer to these membranes as air-gap membranes since the species diffuse across an air layer defined by the membrane porous structure. With air-gap membranes the effective electrode area, $A$, and membrane thickness, $m$, will be different from the gross membrane dimensions. The effective open area (typically $60 \mathrm{per}$ cent) and the tortuosity of the diffusion through the membrane must be taken into account.

The second group comprises homogeneous plastic films in which the diffusing molecule crosses the membrane by first dissolving in the membrane phase (typical films include Teflon, silicone rubber and Mylar). The choice of membrane will depend on which membrane gives the most favourable value of $D k$ (equation 8), as the time response of the electrode will be linearly dependent on this quantity. If we consider electrodes in which $\mathrm{d} C_{\mathrm{B}} / \mathrm{d} C$ is very small and further confine our attention to concentration changes in which $\Delta C / C_{2}$ is virtually equal to one, then $t_{0}{ }_{1}$, for typical values of $m=10^{-2} \mathrm{~cm}$ and $l=10^{-3} \mathrm{~cm}$, will be about 1 minute if the value of $D k$ is $10^{-6} \mathrm{~cm}^{2} \mathrm{~s}^{-1}$. This represents a rough, lower useful limit of $D k$ for an analytically useful electrode.

For air-gap membranes, values for $D$ for various species can be estimated. in the absence of measured values, from interpolation of plots of $D$ against the reciprocal of the square root of the molecular weight. For species in the molecular weight range of 10 to 100 , diffusing into air, $D$ varies from about 0.2 to $0.1 \mathrm{~cm}^{2} \mathrm{~s}^{-1}$ at 1 atmosphere pressure. The partition coefficient $k$, in the absence of gas solubility measurements, can be roughly calculated from free energy of formation and solution data. In the case of homogeneous membranes, values for $D$ and $k$ cannot be calculated, and few tabulated values are available.

Table 2. The diffusion and partition parameters of carbon dioxide and oxygen for three different membranes

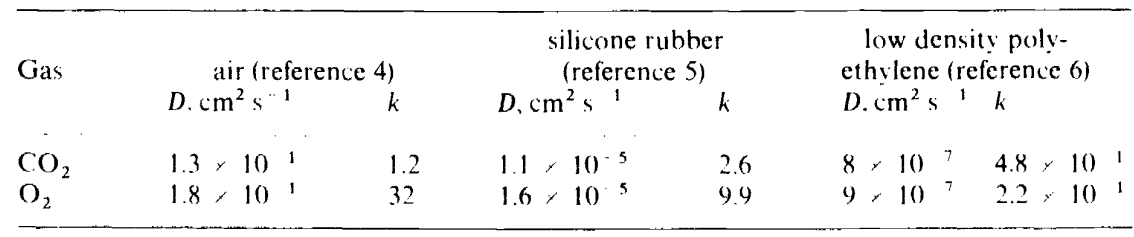

The $k$ values were calculated wherever possible from solubility data in Soluhilities of Inorsanic and Metal-Orqunic (ompounds 4th Fd. W R Link. Ed. American (hemical Societs. 1958 Other values were estimated using free energ data in Sollected Valkes

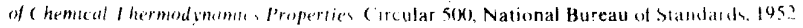


Gas permeabilities, $P_{\mathrm{R}}$, which are proportional to $D k$, are frequently reported, and can be used for estimating electrode time response.

In Table 2 we list $D$ and $k$ values of carbon dioxide and oxygen for three membranes: air, dimethyl silicone rubber ( 25 per cent), and low density polyethylene. In general, we wish to have as large a value for $D k$ as possible. The data show that the air-gap membrane has a clear superiority over the homogeneous membranes, at least for these two gases. The greatest factor involved is the much larger value of the diffusion coefficient in the gas phase. Silicone rubber is unique in having much larger values of diffusion coefficients than other homogeneous membranes, of which polyethylene is typical. Even

Table 3. The diffusion-partition parameters of thirteen gases for air gap and dimethylsilicone rubber membranes

\begin{tabular}{lcc}
\hline $\mathrm{Gas}$ & $\begin{array}{c}\text { air (reference 4) } \\
k D . \mathrm{cm}^{2} \mathrm{~s}^{-1}\end{array}$ & $\begin{array}{c}\text { Dimethyl silicone } \\
\text { rubber }(25 \%) \\
k D, \mathrm{~cm}^{2} \mathrm{~s}^{-1}\end{array}$ \\
$\mathrm{O}_{2}$ & 58 & $1.6 \times 10^{-4}$ \\
$\mathrm{CO}_{2}$ & $1.6 \times 10^{-1}$ & $2.9 \times 10^{-5}$ \\
$\mathrm{H}_{2} \mathrm{~S}$ & $7.7 \times 10^{-2}$ & $3.4 \times 10^{-5}$ \\
$\mathrm{C}_{2}$ & $5.4 \times 10^{-2}$ & \\
$\mathrm{SO}_{2}$ & $3.7 \times 10^{-3}$ & $3.8 \times 10^{\circ}$ \\
$\mathrm{NO}_{2}$ & $2.2 \times 10^{-3}$ & $1.0 \times 10^{-6}$ \\
$\mathrm{HF}$ & $9.9 \times 10^{-4}$ & \\
$\mathrm{NH}_{3}$ & $5.3 \times 10^{-4}$ & $9.8 \times 10^{-8}$ \\
$\mathrm{CH}_{3} \mathrm{NH}_{2}$ & $3.3 \times 10^{-4}$ & \\
$\mathrm{HCN}$ & $3.3 \times 10^{-4}$ & \\
$\mathrm{HOAc}$ & $2.5 \times 10^{-6}$ & \\
$\mathrm{H}_{2} \mathrm{O}$ & $1.3 \times 10^{-7}$ & $5.1 \times 10^{-9}$ \\
$\mathrm{HCl}$ & $2.3 \times 10^{-9}$ & \\
\hline
\end{tabular}

so, $D$ values are typically $10^{4}$ times smaller than in air-gap membranes. At present, therefore, air-gap membranes are the most attractive, although silicone rubber can be used in some applications. Table 3 lists values of $D k$ for air and silicone rubber membranes for a variety of diffusing species.

\section{INTERNAL ELECTROLYTES}

For a given diffusing species $S$, an electrolyte is chosen such that $S$ on diffusing into the internal electrolyte will participate in an equilibrium

$$
s \mathrm{~S}+a \mathrm{~A} \rightleftharpoons i \mathrm{I}+s \mathrm{~S}_{\mathrm{B}}
$$

where $\mathrm{I}$ is an ion sensed by the electrode. The concentration of $\mathrm{I}$ is given by

$$
[\mathrm{I}]=\left[\frac{K[\mathrm{~A}]^{a}}{\left[\mathrm{~S}_{\mathrm{B}}\right]^{s}}\right]^{(s / i)}[\mathrm{S}]^{(s / i)}
$$

If the species $A$ and $S_{B}$ are present at high concentrations relative to $I$ and are themselves impermeable to the membrane, the $\left[\mathrm{S}_{\mathrm{B}}\right]$ and $[\mathrm{A}]$ will be virtually constant in response to changes in $\mathrm{S}$ and, [I] will be proportional to [S$]^{s / i}$. Given this state of affairs, the electrode will show a Nernstian response to $S$ 
with a slope of $2.3(R T / \mathrm{F})(\mathrm{s} / \mathrm{i})$ millivolts per decade change in $\mathrm{S}$. Hence the electrode sensitivity is determined by the stoichiometric ratio $s / i$.

The requirement for constancy of concentration of $S_{B}$ and $A$ is equivalent to requiring that the equilibrium constant $K$ be not too large, i.e., the equilibrium reaction 9 should not lie too far to the right. At the same time, it is necessary that $K$ be not so small that [I] falls below the limit of detection at lower levels of $S_{1}$ of the sensing electrode. Optimization of electrolyte composition inevitably requires some compromise on this point.

The simple equilibrium expression in equation 10 , in practice, will only hold over a limited range of [S]. At sufficiently low concentrations of [S], for example, $\left[\mathrm{S}_{\mathrm{B}}\right]$ will ultimately decrease and the condition of constancy of $\mathrm{S}_{\mathrm{B}}$ will no longer hold. In addition, there may be other equilibria involving $A$ or $S_{B}$, which may be important over some ranges of [S]. In either event, the sensitivity will become a function of [S], and the derivative $\mathrm{d} C_{\mathrm{B}} / \mathrm{d} C$ (cf equation 8 (in this example $\mathrm{dS}_{\mathrm{B}} / \mathrm{dS}$ )) will not be zero; i.e., the time response of the electrode will increase.

Evaluation of sensitivity and time response requires the simultaneous solution of all the pertinent equilibrium and conservation equations, and the condition for electroneutrality. Such a solution gives [I] as a function of [S] which is equivalent to the calibration curve of the electrode, and also $\left[\mathrm{S}_{\mathrm{H}}\right.$ ] as a function of [S] which can be differentiated to give $\mathrm{dS}_{\mathrm{B}} / \mathrm{dS}$. Except for the simplest systems, the calculation is extremely tedious, and it may be more expedient to determine calibration curves and time response characteristics by experiment.

\section{A MODEL FOR THE SULPHUR DIOXIDE ELECTRODE}

As an example of a gas sensing electrode system, we take the case of a sulphur dioxide sensing electrode. By analogy with the Severinghaus electrode, we might consider a bisulphite solution as a possible electrolyte in which, hopefully, the principal equilibrium is

$$
\mathrm{SO}_{2}+\mathrm{H}_{2} \mathrm{O} \Rightarrow \mathrm{HSO}_{3}^{-}+\mathrm{H}^{+}
$$

and a $\mathrm{pH}$ electrode would respond in a Nernstian manner to changes in sulphur dioxide. For the general case we must also consider the effect of sulphite formation which can become important at low sulphur dioxide levels, and additionally, the possibility of bisulphite increasing above its initial value at high concentrations. The pertinent equilibrium equations are

$$
\begin{aligned}
& {\left[\mathrm{SO}_{2}\right]=K_{\mathrm{p}}\left[\mathrm{H}^{+}\right]\left[\mathrm{HSO}_{3}^{-}\right]} \\
& {\left[\mathrm{HSO}_{3}^{-}\right]=K_{1}\left[\mathrm{H}^{+}\right]\left[\mathrm{SO}_{3}^{2-}\right]} \\
& {\left[\mathrm{H}^{+}\right]\left[\mathrm{OH}^{-}\right]=K_{\mathrm{w}}}
\end{aligned}
$$

In addition, we have the condition of electrical neutrality. Using a sodium bisulphite internal solution of concentration $\mathrm{N}$, the condition is :

$$
\mathrm{N}+\left[\mathrm{H}^{+}\right]=\left[\mathrm{HSO}_{3}^{-}\right]+2\left[\mathrm{SO}_{3}^{2-}\right]+\left[\mathrm{OH}^{-}\right]
$$

Elimination of variables gives $\left[\mathrm{H}^{+}\right]$as a function of $\left[\mathrm{SO}_{2}\right]$. Several plots of this function for various values of $\mathrm{N}$ are shown in Figure 4 . 


\section{GAS ELECTRODES}

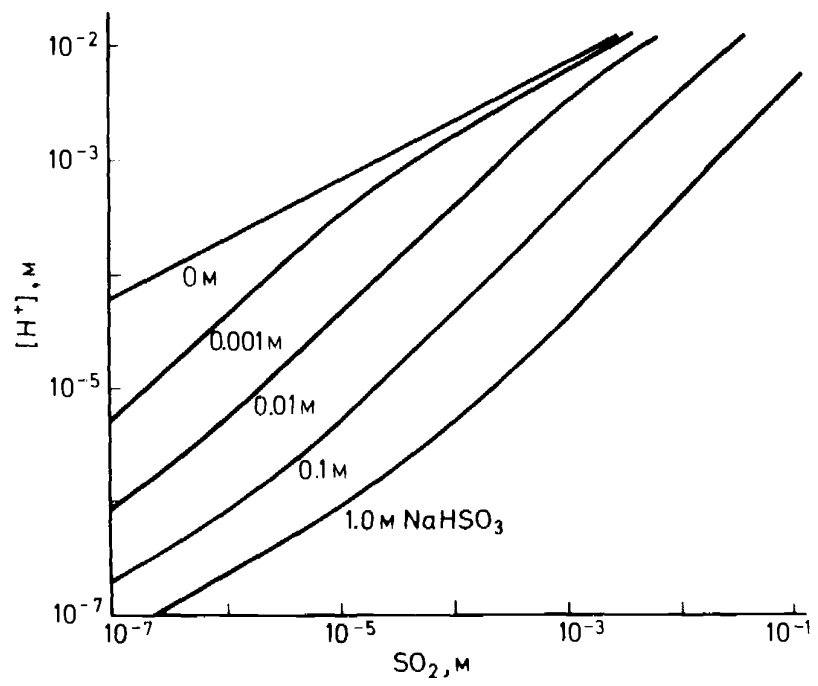

Figure 4. Sulphur dioxide electrode response as a function of internal electrolyte concentration for $\mathrm{p} K_{\mathrm{p}}=1.9$ and $\mathrm{p} K_{1}=6.8$.

These curves are identical in shape with expected calibration curves. Depending on the value of $\mathrm{N}$ and $\left[\mathrm{SO}_{2}\right]$ the electrode sensitivity will vary from a maximum of 1.0 to a minimum of $0.5 \mathrm{pH}$ units change per decade change in $\left[\mathrm{SO}_{2}\right]$. The high values of $\mathrm{N}$ show unit $\mathrm{pH}$ sensitivity at high values of $\left[\mathrm{SO}_{2}\right]$ while more dilute solutions given the unit $\mathrm{pH}$ sensitivity at low values of $\left[\mathrm{SO}_{2}\right]$. Figure 4 predicts that an electrolyte about $10^{-2} \mathrm{M}$ in bisulphite will give the most nearly linear response over the greatest range. Response curves of actual electrodes are in excellent agreement with the calculated values.

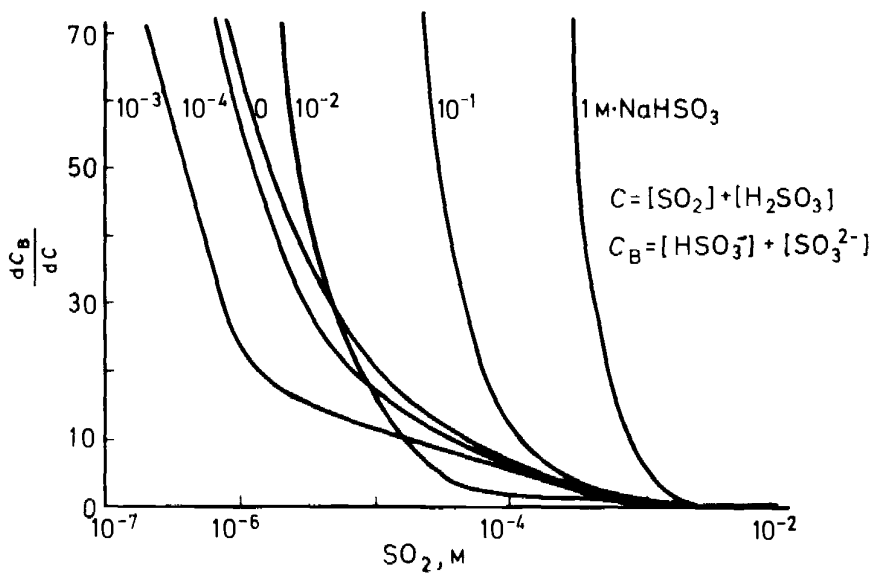

Figure 5. Sulphur dioxide electrode time response parameter. 
In Figure 5 we show calculated values of $\mathrm{d} C_{\mathrm{B}} / \mathrm{d} C$, which in this case is equal to

$$
\frac{\mathrm{d}\left[\left[\mathrm{HSO}_{3}^{-}\right]+\left[\mathrm{SO}_{3}^{2-}\right]\right]}{\mathrm{d}\left[\mathrm{SO}_{2}\right]}
$$

as a function of $\left[\mathrm{SO}_{2}\right]$ for various values of $\mathrm{N}$. $\mathrm{d} C_{\mathrm{B}}$ tends to increase dramatically as $\left[\mathrm{SO}_{2}\right]$ decreases, more seriously so at higher values of $\mathrm{N} . \mathrm{d} C_{\mathrm{B}} / \mathrm{d} C$ exceeds 50 at concentrations of $\mathrm{SO}_{2}$ of the order of $10^{-3} \mathrm{M}$ when $\mathrm{N}$ is $1 \mathrm{M}$. Thus we would expect from equation 8 that the response of an electrode using a $1 \mathrm{M}$ internal filling solution would be fifty times slower than an electrode using a $0.01 \mathrm{~m}$ filling solution. For any value of $\mathrm{N}$ the rapid rise of $\mathrm{d} C_{\mathrm{B}} / \mathrm{d} C$ effectively imposes a lower limit of detection due to slow electrode response. Surprisingly, increasingly dilute filling solutions do not lead to faster electrodes for low level sulphur dioxide measurements. The observed time responses of actual electrodes as a function of bisulphite concentration are in qualitative agreement with the predicted values.

\section{CHARACTERISTICS OF GAS SENSING ELECTRODES}

A number of gas sensing electrodes have been constructed and evaluated. and their performance is summarized in Table 4. These electrodes are made using the Orion series 95 gas sensing electrode format, as shown in Figure 6. The electrode outer body and bottom cap are made of a fluorocarbon plastic for impact and chemical resistance, while the sensing and reference electrodes are housed in an epoxy inner body. A second ion sensitive electrode is used as the reference electrode, and is located in the internal electrolyte reservoir consisting of the space between the inner and outer bodies. The electrolyte contains a fixed level of the ion to which the reference electrode responds. For example, the ammonia and sulphur dioxide electrodes use a silver chloride reference electrode and internal electrolyte containing chloride ion.

The air-gap membrane is held in place inside the bottom cap by the spacer. In addition to holding the membrane in place, the spacer positions the sensing element and controls the depth of penetration of the sensing element into the membrane, thereby setting the thickness of the layer of internal electrolyte trapped between the membrane and the sensing element.

Referring again to Table 4, if the sensing element is indicated as $\mathrm{H}^{+}$it is a $\mathrm{pH}$ electrode with a surface ground to nearly optical flatness. Other electrodes use a variety of flat ion sensitive elements : hydrogen cyanide electrodes use a silver sulphide sensing electrode, the hydrogen fluoride electrode uses a lanthanum fluoride sensing electrode, and the chlorine electrode uses a silver chloride sensing electrode.

The hydrogen cyanide electrode uses a silver sulphide electrode to sense the activity of silver ion in equilibrium with a silver cyanide complex in the internal electrolyte. As cyanide diffuses across the membrane, the activity of silver ion will decrease as the square of the cyanide ion in the internal electrolyte, giving an electrode slope of approximately $120 \mathrm{mV}$. The indicator technique for determining cyanide has been discussed in detail elsewhere ${ }^{7.8}$.

Each of the internal filling solutions has been chosen to allow the electrode to operate using one of the equilibria shown in Table 1. 


\section{GAS ELECTRODES}

Table 4. Some specifications of gas sensing electrodes

\begin{tabular}{|c|c|c|c|c|c|c|c|}
\hline $\begin{array}{l}\text { Species } \\
\text { sensed }\end{array}$ & Sensor & $\begin{array}{l}\text { Internal } \\
\text { electrolyte }\end{array}$ & $\begin{array}{l}\text { Lower } \\
\text { limit, M }\end{array}$ & Slope & $\begin{array}{l}\text { Sample } \\
\text { preparation }\end{array}$ & Interferences & Applications \\
\hline $\mathrm{CO}_{2}$ & $\mathrm{H}^{+}$ & $0.01 \mathrm{M} \mathrm{NaHCO}$ & $-10^{-5}$ & +60 & $<\mathrm{pH} 4$ & & $\begin{array}{l}\text { blood, } \\
\text { fermentation } \\
\text { vats }\end{array}$ \\
\hline $\mathrm{NH}_{3}$ & $\mathbf{H}^{+}$ & $0.01 \mathrm{M} \mathrm{NH}_{4} \mathrm{Cl}$ & $-10^{6}$ & -60 & $>\mathrm{pH} 11$ & $\begin{array}{l}\text { volatile } \\
\text { amines }\end{array}$ & $\begin{array}{l}\text { soil, water, } \\
\text { Kjeldahl } \\
\text { analyses }\end{array}$ \\
\hline $\mathrm{Et}_{2} \mathrm{NH}$ & $\mathrm{H}^{+}$ & $0.1 \mathrm{M} \mathrm{Et}_{2} \mathrm{NH}_{2} \mathrm{Cl}$ & $-10^{-5}$ & -60 & $>\mathrm{pH} 11$ & $\mathrm{NH}_{3}$ & $*$ \\
\hline $\mathrm{SO}_{2}$ & $\mathrm{H}^{+}$ & $0.01 \mathrm{M} \mathrm{NaHSO}$ & $-10^{-6}$ & +60 & $\begin{array}{l}\mathrm{HSO}_{4} \\
\text { buffer }\end{array}$ & $\begin{array}{l}\mathrm{Cl}_{2}, \mathrm{NO}_{2} \\
\text { must be } \\
\text { destroyed } \\
\left(\mathrm{N}_{2} \mathrm{H}_{4}\right)\end{array}$ & $\begin{array}{l}\text { stack gases, } \\
\text { foods, wines, } \\
\mathrm{S} \text { in fuels }\end{array}$ \\
\hline & $\mathbf{H}^{+}$ & $0.1 \mathrm{M} \mathrm{NaHSO}_{3}$ & $-10^{-4}$ & & & & \\
\hline $\mathrm{NO}_{2}$ & $\mathbf{H}^{+}$ & $0.02 \mathrm{M} \mathrm{NaNO}_{2}$ & $-5 \times 10^{7}$ & +60 & citrate buffer & $\begin{array}{l}\mathrm{SO}_{2} \text { must be } \\
\text { destroyed } \\
\left(\mathrm{CrO}_{4}^{2-}\right) \mathrm{CO}_{2} \\
\text { interferes }\end{array}$ & $\begin{array}{l}\text { stack gases, } \\
\text { ambient air } \\
\text { (after scrub- } \\
\text { bing), nitrite } \\
\text { in foods }\end{array}$ \\
\hline $\mathrm{H}_{2} \mathrm{~S}$ & $\mathrm{~S}^{2-}$ & $\begin{array}{l}\text { citrate buffer } \\
\text { (pH 5) }\end{array}$ & $-10^{-8}$ & -30 & $<\mathrm{pH} 5$ & $\begin{array}{l}\mathrm{O}_{2} \text { (ascorbic } \\
\text { acid must be } \\
\text { added to } \\
\text { samples) }\end{array}$ & $\begin{array}{l}\text { pulping } \\
\text { liquors, } \\
\text { anaerobic } \\
\text { muds, } \\
\text { fermentation }\end{array}$ \\
\hline $\mathrm{HCN}$ & $\mathbf{A g}{ }^{+}$ & $\mathrm{KAg}(\mathrm{CN})_{2}$ & $-10^{7}$ & -120 & $<\mathrm{pH} 7$ & $\begin{array}{l}\mathrm{H}_{2} \mathrm{~S} \\
\left(\mathrm{add} \mathrm{Pb}^{2+}\right)\end{array}$ & $\begin{array}{l}\text { plating baths, } \\
\text { plating wastes }\end{array}$ \\
\hline $\mathrm{HF}$ & $\mathrm{F}^{-}$ & $1 \mathrm{MH}^{+}$ & $-10^{-3}$ & -60 & $<\mathrm{pH} 2$ & & $\begin{array}{l}\text { etching baths, } \\
\text { steel pickling }\end{array}$ \\
\hline HOAC & $\mathrm{H}^{+}$ & $0.1 \mathrm{M} \mathrm{NaOAc}$ & $-10^{-3}$ & +60 & $<\mathrm{pH} 2$ & & $\dagger$ \\
\hline $\mathrm{Cl}_{2}$ & $\mathrm{Cl}^{-}$ & $\mathrm{HSO}_{4}$ buffer & $5 \times 10^{-3}$ & -60 & $<\mathrm{pH} 2$ & & bleaching \\
\hline
\end{tabular}

* example of volatile weak base electrode.

+ example of volatile weak acid elect ode

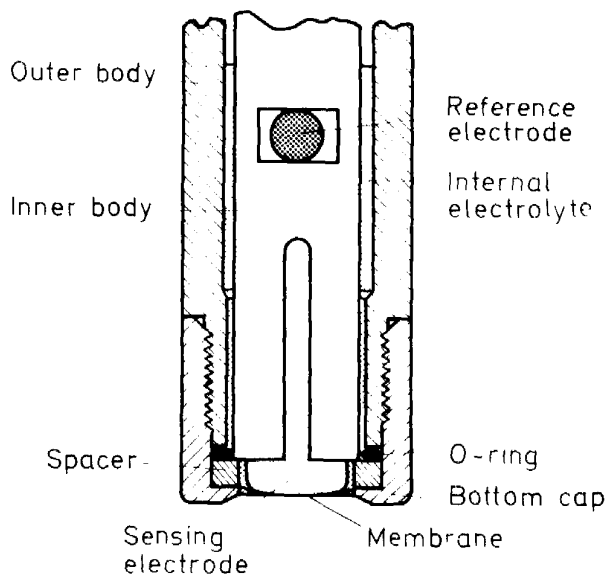

Figure 6. Construction of Orion series 95 gas sensing electrode. 
The lower limit is defined as the apparent concentration indicated by the electrode in a zero concentration solution after five minutes, coming from a solution with a concentration of $10^{-2} \mathrm{M}$ of the gas sensed. In general, observed time responses are faster as the level of the gas sensed increases, and are faster for increasing concentrations than for decreasing concentrations. Electrode time response is an important consideration when a gas sensing electrode is used for routine laboratory analysis. As a rule of thumb, an adequate electrode for routine laboratory use is one which reaches 99 per cent of the final reading in 2 to 3 minutes for a ten-fold increase in the concentration of the species sensed. This time response characteristic is observed with the ammonia, sulphur dioxide, and nitrogen dioxide electrodes at the $10^{-4} \mathrm{M}$ level and above; with the hydrogen cyanide electrode at $10^{-5} \mathrm{M}$ and above; and at $10^{-6} \mathrm{M}$ and above for the hydrogen sulphide electrode. 99 per cent time response for the hydrogen fluoride electrode is 5 to 10 minutes in the range $10^{-3} \mathrm{M}$ to $10^{\circ} \mathrm{M}$. Response of the chlorine electrode is likewise slow.

While time response characteristics are important for laboratory applications, they are less critical for continuous monitoring; and electrodes with 99 per cent time responses of the order of 30 minutes are useful.

The slope given is the approximate change in potential at $29^{\circ} \mathrm{C}$ for a tenfold increase in the gas concentration within the range in which the electrode response is apparently Nernstian.

Sample preparation includes adjusting the $\mathrm{pH}$ to a range in which the gas measured is present principally as the dissolved gas and not as ionic species which are in equilibrium with the gas. In the case of the sulphur dioxide electrode, the relatively low value of the $\mathrm{p} K$ for sulphurous acid (about 1.9) presents a problem. To convert sulphite and bisulphite almost completely to sulphur dioxide requires lowering the $\mathrm{pH}$ to about zero. This necessitates the addition of large amounts of acid to the sample if the sample is not already very acidic. Because of the hazards of handling concentrated acid, we have adopted the alternative procedure of adding a concentrated sulphate-bisulphate buffer to the sample. The buffer adjusts the solution to a $\mathrm{pH}$ close to that of the $\mathrm{p} K$. While the sulphur dioxide level in the solution is reduced to about half the level that would be present with a concentrated strong acid added, no discernible loss in electrode sensitivity is observed. Standardizing solutions for the sulphur dioxide electrode are prepared by adding the buffer to standard sodium sulphite solutions.

\section{PRACTICAL CONSIDERATIONS}

As shown in Table 2, the high rate of gas transport clearly makes the air-gap membrane more suitable for gas sensing electrodes than the homogeneous type of membrane, especially for measurements at lower concentrations.

For measurements of aqueous solutions, the air-gap membrane must have hydrophobic surfaces and small pore diameters so that water is excluded from entering the membrane as much as possible. (If measurements are to be made in organic solvents a hydrophilic membrane is called for, along with an organic internal electrolyte system.)

The hydrophobic air-gap membrane exhibits one drawback with respect 


\section{GAS ELECTRODES}

to homogeneous membranes. With time, the membrane will 'wet through' allowing the sample solution to come into contact with the internal electrolyte. The membrane life in solutions containing wetting agents is considerably shortened. For example, a porous Teflon membrane, as used in the Orion ammonia electrode, has a life well in excess of two months when used under normal laboratory conditions in solutions not containing wetting agents. In a solution containing three drops of a non-ionic wetting agent, Triton $\mathrm{X}-100$, per litre, the life of the Teflon membrane is lowered to about four days.

Water is a gas which is also transported across the membrane. Table 3 shows that the $k D$ value for water is much lower than for most gases. Nevertheless, aqueous solutions are about $55 \mathrm{M}$ in water, making water a potential electrode interference. If water vapour transport results in dilution, or concentration, of the internal electrolyte and this in turn alters parameters in the equilibrium equation, electrode instability and drift will be observed.

Two conditions will give rise to water transport ; first, differences between the internal electrolyte and sample solution osmolality; and second, differences in sample solution and electrode temperature. Our calculations indicate that the rate of water transport per $0.1 \mathrm{M}$ difference in osmolality is about $1.1 \times 10^{-7} \mathrm{ml} \mathrm{s}^{-1} \mathrm{~cm}^{-2} \mathrm{~mm}^{-1}$ of membrane thickness. Water transport at $25^{\circ} \mathrm{C}$ per $1{ }^{\circ} \mathrm{C}$ difference in sample and electrode temperatures is about $3.6 \times 10^{-6} \mathrm{ml} \mathrm{s}^{-1} \mathrm{~cm}^{-2} \mathrm{~mm}^{-1}$ of membrane thickness. These rates of water transport are quite significant compared to the $10^{-2}-10^{-3} \mathrm{ml}$ volume of electrolyte between the sensing electrode and the membrane. Optimal electrode performance is obtained by adjusting the sample osmolality to that of the internal electrolyte, and by keeping the electrode and sample temperatures close together. The effect of sample osmotic pressure on the response of gas sensing electrodes can be used to advantage, under appropriate conditions, to measure osmolality.

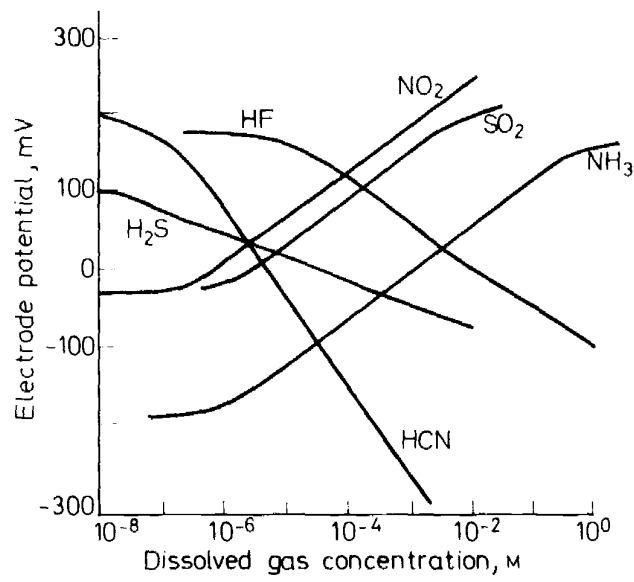

Figure 7. Working curves for various gas sensing electrodes. 


\section{ANALYTICAL METHODS}

Measurements with gas sensing electrodes are carried out using the same basic analytical methods employed with ion sensitive electrodes; sample $\mathrm{pH}$ adjustments are made to free the species measured, and instead of an ionic strength adjustor (ISA), an osmotic strength adjustor (OSA) is used.

Direct electrode measurements can be made using working curves which have been prepared by plotting electrode potential versus concentration of dissolved gaseous species on semilogarithmic graph paper. Examples of working curves obtained for the various electrodes are shown in Figure 7.

The known addition method can be used with the concentration of the gas being determined by calculation or from tables using the observed change in potential when a known volume of standardizing solution is added to a known volume of sample.

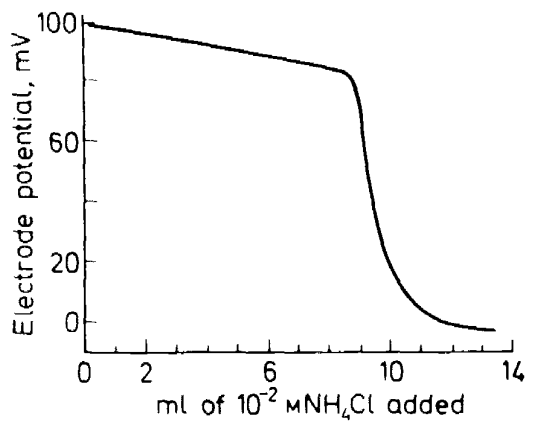

Figure 8 . Titration of $100 \mathrm{ml}$ of $10^{-3} \mathrm{M}$ sodium hypochlorite with ammonium chloride using the Orion model 9510 ammonia electrode.

Gas sensing electrodes can be used as end-point detectors in titrations as shown in Figure 8 . A basic $10^{-3} \mathrm{M}$ hypochlorite is titrated with a $10^{-2} \mathrm{M}$ ammonium chloride solution, using an Orion ammonia electrode to follow the level of ammonia.

\section{DISCUSSION}

A number of new potentiometric gas sensing electrodes have been developed with the aid of a model which predicts the time response characteristics and the electrode potential versus concentration behaviour. The basic gas electrode configuration using an air-gap membrane and an ion sensitive electrode can be used to measure a large number of dissolved species.

Most of these electrodes are free of interferences with proper choice of internal electrolyte and the sample preparation.

In addition to being used to measure dissolved gases, the electrodes can be used to measure water-saturated gas streams. Gas sensing electrodes are free of liquid junction potential problems associated with $\mathrm{pH}$ and ion sensitive electrodes, and are free of redox interferences. Limits of detection 


\section{GAS ELECTRODES}

for these electrodes frequently equal or better conventional analytical techniques.

We feel that these electrodes will find wide application in laboratory and process analysis and in research.

\section{REFERENCES}

' L. C. Clark. Trans. Am. Soc. Artificial Internal Organs 2. 41 (1956).

2 R. W. Stow, R. F. Baer and B. F. Randall. Arch. Phys. Med. Rehabil. 38, 646 (1957); W. Severinghaus and A. F. Bradley, J. App. Physiol. 13, 515 (1958).

3 Orion Research Inc. Instruction Manual 95-10 (1971); Electronic Instruments Ltd. Instruction Manual (1970).

4 Handbook of Chemistry and Physics. Chemical Rubber Co. Ohio. 48th Edition 1968.

5 W. L. Robb. General Electric Technical Report No. 65-C-031 (1956).

6 A. S. Michaels and H. J. Bixler. J. Polymer Sci. 4, 413 (1961).

7 M. S. Frant, J. W. Ross and J. H. Riseman. Anal. Chem. 44, 10 (1972).

8 J. H. Riseman. Am. Lab. 4, 63, 1972. 